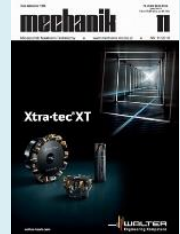

Author: Michał Wieczorowski

Title of article: „Digitalizacja powierzchni w aplikacjach mikro, mezo i makro” (“Digitalization of surfaces in micro, meso and macro applications")

Mechanik, Vol. 91, No. 11 (2018): pages 944-949

DOI: https://doi.org/10.17814/mechanik.2018.11.166

\title{
Digitalization of surfaces in micro, meso and macro applications
}

\author{
Digitalizacja powierzchni w aplikacjach mikro, mezo i makro
}

\section{MICHAK WIECZOROWSKI *}

In the paper a concept of length and angle metrology in fourth industrial revolution known as Industry 4.0 was presented. Problems and conditions as well as limitations connected with measurement possibilities from devices and man point of view were shown. Scale as metrology term with its division to different ranges, i.e. macro, micro and meso were described. For each of these areas digitization and its tasks were presented.

KEYWORDS: digitization, scale, Industry 4.0

The fourth industrial revolution, the slogans of which have been appearing for several years, is slowly taking its first steps in the field of practical activities. As usual, the driving force behind the actions taken is the financial and image effects, that is, on the one hand, the increase in productivity, and on the other - better awareness of our products and actions oriented towards satisfying the increasingly sophisticated needs of customers.

In earlier revolutions, one impulse changed the entire value chain, and this time, a series of technologies and different behaviors overlap, which, when integrated, lead to a new look at the production of goods and services. Thus, Industry 4.0 distinguishes itself that it combines technologies and blurs the boundaries between the physical, digital and biological spheres of manufacturing processes [1]. The metro-logy must also be adapted to these requirements as a set of tools verifying the quality and dimensional compliance of the products obtained.

\section{Vision of metrology in Industry 4.0 strategy}

Rising production capabilities are conducive to generating increasingly bolder shapes. This applies not only to external elements that testify to the vision of design (e.g. housing of household appliances, car bodies), but also parts produced on multi-axial production centers. During construction, more and more free surfaces appear, which can not be described by a curve or surface equation, therefore the description is replaced by a point cloud. Geometric solids, the description of which has become characteristic parameters, are also processed in the form of a data set, thanks to which the operator receives information

* Prof. dr hab. inż. Michał Wieczorowski (michal.wieczorowski@put.poznan.pl) - Politechnika Poznańska on the basis of their deviations in individual places on a regular basis. In this way, the Industry 4.0 doctrine forces a new approach to metro-logy, based on a point cloud or a triangle grid based on them (.stl file).

One of the basic elements of such a strategy is the processing of large data sets. The mere possibility of using such collections is the result of the development of length and angle subway and the emergence of measuring instruments based on various physical principles over the last dozen or so years, which allow collecting large numbers of coordinates of measurement points in a relatively short time. And because in most people deeply rooted is the passion for collecting things and goods, and the conviction that the more, the better (unfortunately not always right), then more willingly are adopted new matrix options with mega pixels or voxels, innovative generations measuring instruments and software cooperating with them.

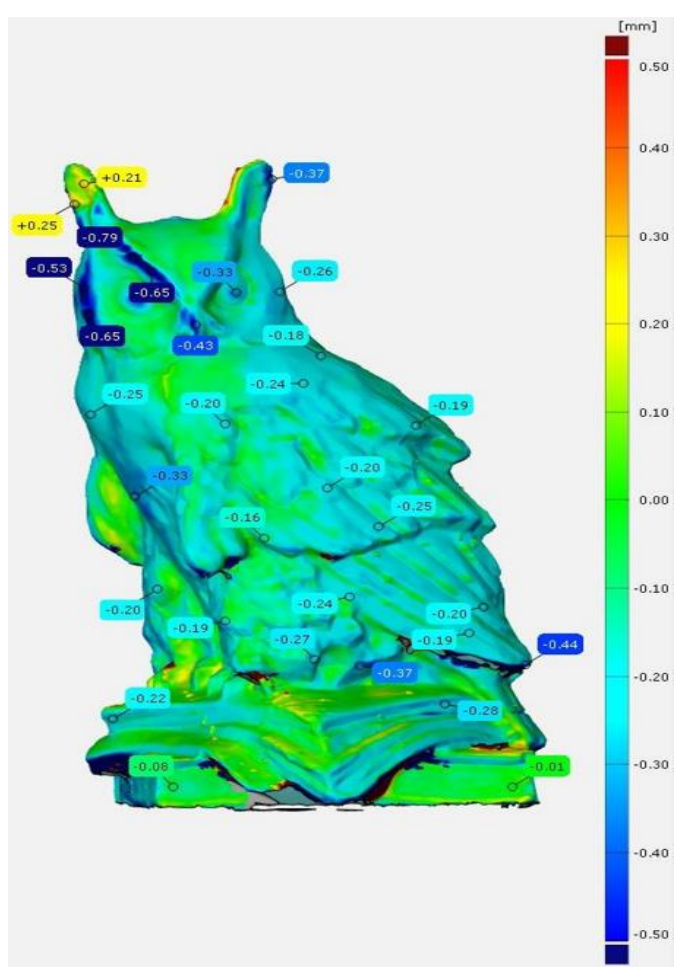

Fig. 1. Colorful map of deviations of the object based on free surfaces [2] 
Generating and processing large files requires the use of powerful computing units, very fast and with a capacious memory of graphic cards, as well as large external memory, necessary for archiving the collected measurement data. That is why more and more often, the analysis of individual dimensions departs, limiting the imposition of the obtained data on the nominal file from the CAD application and the visual assessment of the color deviation map - especially for objects having many free surfaces (fig. 1).

In this approach, the measurement reports and the obtained data are not therefore numbers and parameter values, but surfaces.

Developing the convictions created several decades ago in the introduction of quality assurance systems that the weakest link in the new systems of manufacturing and product evaluation is man, also in the metrological strategy of Industry 4.0, human influence should be important at the stage of constructing and creating programs for technological machines and measuring devices, but in the course of their operation it is to be reduced to supporting activities. Increasingly, producers are aware of the shortage of professionals, which encourages them to look for alternative solutions, including the use of robots.

However, in order for man to be able to function safely in such an environment, the concept of cooperating robots appeared, more and more willingly used in length and angle metrology. They carry out automated measuring activities and support the operator in activities requiring strength or strength. An exemplary measuring scanner with a cooperating robot is shown in fig. 2 .

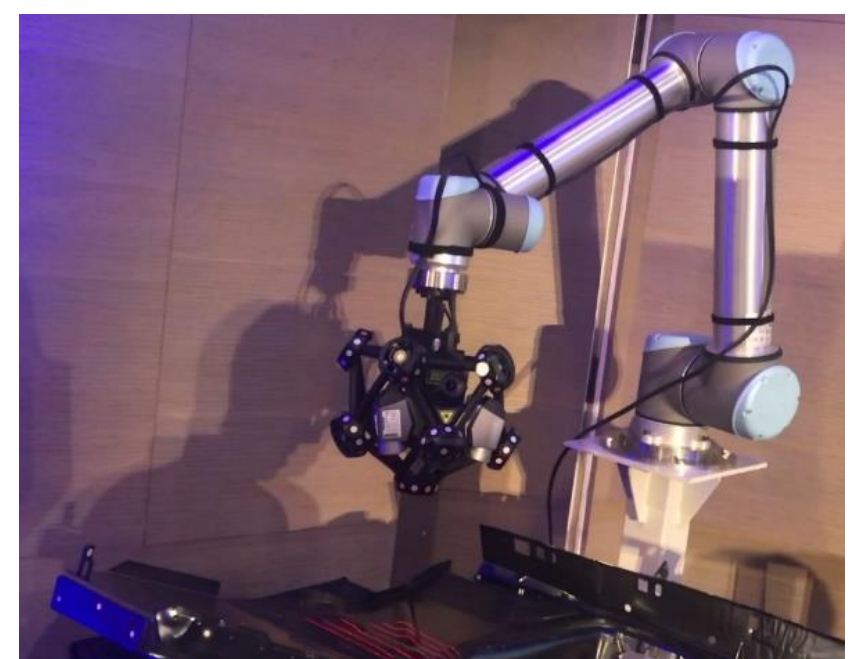

Fig. 2. Scanner with a robot cooperating during the scanning of a pressed element

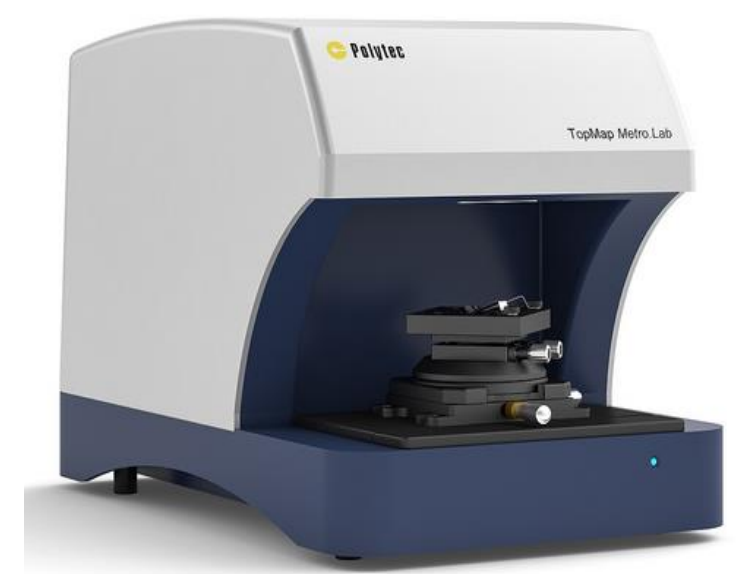

Fig. 3. Movable elements of the optics hidden under the upper cover in the scanning coherence interferometer [3]
An important feature of most cooperating robots is their very easy programming in teaching mode. It consists in memorizing next manually set robot positions and repeating them (at higher speed) in automatic mode.

Another element of the new metrology approach is the strong emphasis on the design of fail-safe systems. The constructor predicts the possibility of collision of moving elements with the object (or other elements of the measuring device) and seeks to hide them - this applies to, for example, elements of mobile optics moving under a special cover (fig. 3).

Due to such protection, the optician does not hit the table or the object on it during the measurements and moving down. For elements that can not be hidden, built-in spring mechanisms are detected, which detect overload at the contact and disable the movement of the sub-systems of the measuring instrument.

\section{Scale in metrology of length and angle}

The term "scale" in science and everyday life is interpreted differently [4]. As a scale (e.g. Celsius) is meant a set of numbers or values used to compare the size (or levels). The scale is also a series of sounds arranged according to a fixed pattern, it expresses the range of the sounds of a given instrument or human voice.

In geography, astronomy, meteorology and statistics, the term scale is used to describe and classify the size dimension (usually the length, distance or area of the surface). Therefore, the object is microscopic if it is too small to be observed with the naked eye, whereas the megatrend in statistics refers to a global phenomenon or a very long time.

In physics, the notion of scale refers to the order of magnitude, while the delimitation is often arbitrary.

Metrologically the scale is treated as a synonym for longitudes (small scale $=$ small length), period of signal from the surface (roughness - small scale, shape error - large scale) or fragment of frequency signal (window with a certain range that can be moved around obtained signal). Long-scale and large scale metrology (macro) refers to measurements of geometric features, small scale (nano and micro) - to non-evenness of the surface, and on an intermediate scale (meso) - to what will be obtained when inequalities begin to transform into geometric elements.

Traditionally, coordinates were included among the instruments used in macro-scale measuring machines and scanners, and micro scale - e.g. profilometers and interferometers. The meso scale included devices to measure shape errors. In recent years, there have been tendencies to expand the ranges of some of the measuring instruments mentioned. Coordinate measuring machines include designs aspiring to the meso scale and even micro scale, while on the other hand profilometers and white light interferometers with a large range allow measuring not only surface irregularities, but also geometrical features in the area of several tens of millimeters.

When digitizing surfaces on any scale, the observed area is calculated as a function of the scale of a series of virtual tile adaptations covering it in a mosaic manner [5]. Areas of plaques or patches re-present spatial scales of observation. The matches are repeated with plates of smaller and smaller areas, in order to determine the observed areas depending on the scale of spatial observations (fig. 4) [6].

The size of the triangular plates or patches depicted on the surface is the scale of observation. The nominal areas, covered by individual tile fittings, are shown at the top of each chart.

Measurements on one scale are conditioned by what happens on the other scales. In this way, full interaction between the scales takes place, which forces the operator (who is also itself an influential factor) to take into account 
such interaction, because - next to the ambient conditions it has an impact on the measurement results (fig. 5).

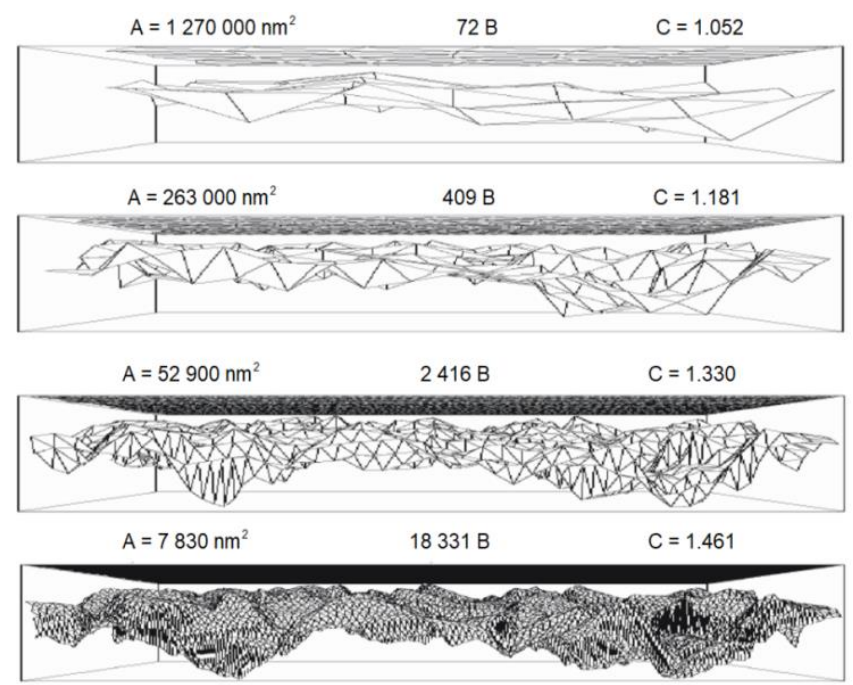

Fig. 4. Surface mapping with tiles of various sizes (scale): $A$ surface, $B$ - number of tiles, $C$ - relative area

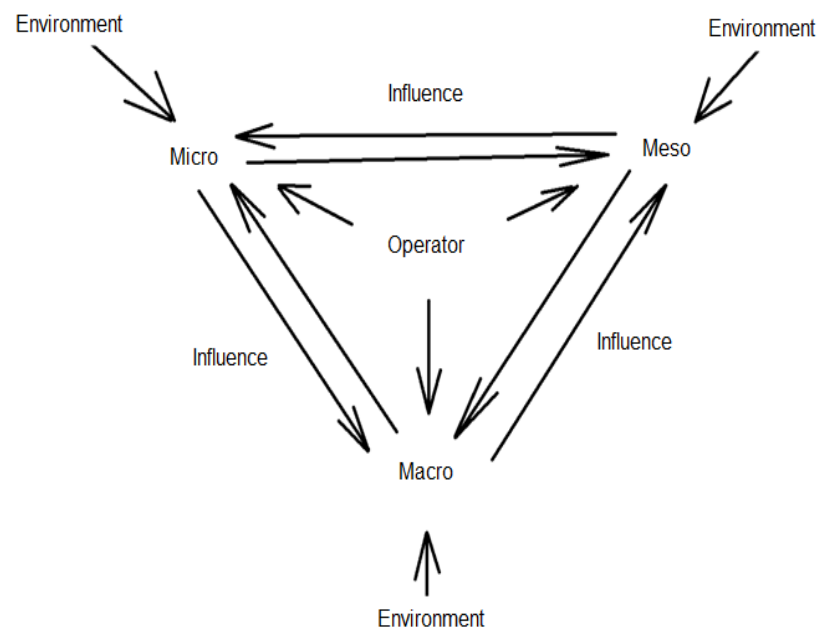

Fig. 5. Interactions occurring between scales in length and angle metrology

In order to obtain comprehensive information about the measured object, it is necessary to analyze it on various scales. In this way, the metrological verification includes geometrical features and shapes as well as surface unevenness. This is a determinant of the emergence of techniques that integrate measurements at various scales, both in terms of hardware and software. The combination of data from various scales in one model allows for the use of the data set obtained in the simulation works taking into account all aspects of contact mechanics.

\section{Analysis in macro scale}

Macro-scale digitalization involves collecting coordinates of measuring points in order to determine geometrical shapes. They can be figures and geometries or free surfaces.

Traditionally used measuring devices are in this case coordinate measuring machines, equipped with contact and optical contacts. The rail in the contact version allows to calculate the maximum permissible errors from the fractions of micrometers, which is still beyond the scope of the possibilities of optical techniques in the macro scale. The disadvantage of the machine is the slow collection of points and contact with the measured surface, which in some situations is unacceptable.
Optical scanners appeared in the $21^{\text {st }}$ century. The first used structural light, and the latest ones are based on the radiation coming from the laser and they work so fast that the user can work on the basis of data sets that are inscribed in big data. Even more information is provided by measurements carried out using computer tomographs (CT), which allow the collection of data not only from visible but also from invisible surfaces of the object and its interior $[7,8]$. Examples of devices working in macro scale are shown in fig. 6.

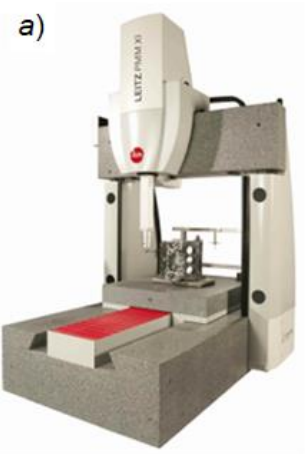

c)

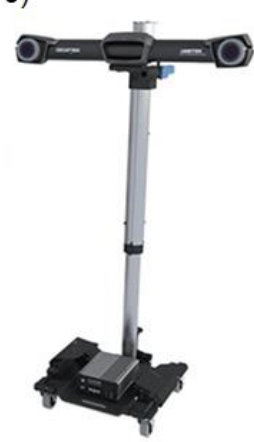

b)

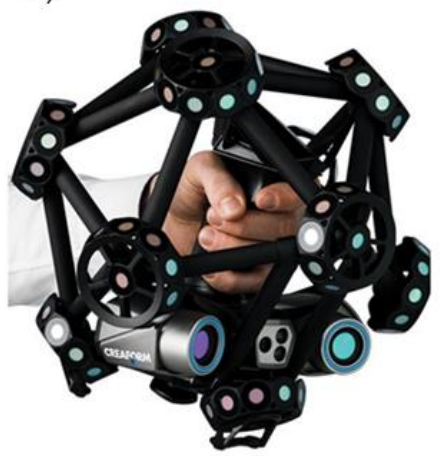

d)

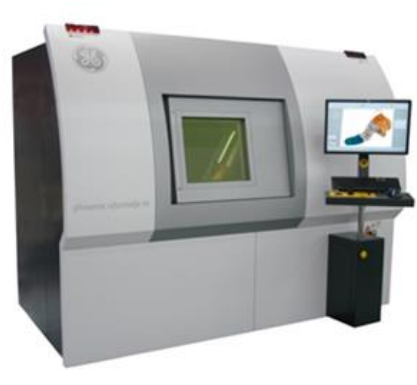

Fig. 6. Measuring devices working in macro scale: a) coordinate measuring machine, $b$ ) laser head of the scanner, $c$ ) tracker for laser head, d) computed tomograph

Automation of the point collection process involves the use of a coordinate measuring machine operating in CNC mode with a loading system and a measuring cell for an optical scanning system (fig. 7). For now, tomographs are very rarely used in industrial serial measurements, but in such situations objects can be placed automatically on a belt transporting them to the measuring space.

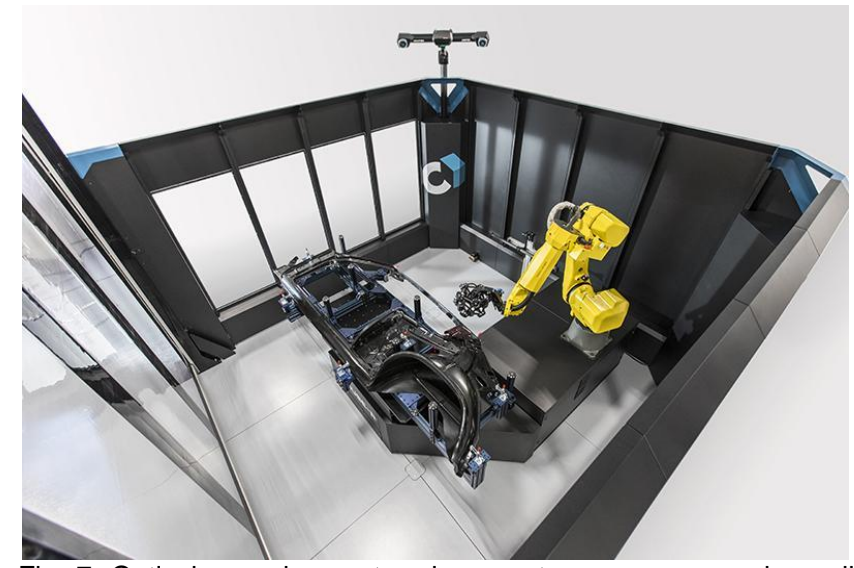

Fig. 7. Optical scanning system in an autonomous measuring cell [9]

The system shown in the picture uses a tracker tracking the position of the laser head, thanks to which it does not require additional markers on the object or holder, and the light ray system allows to simultaneously measure surfaces 
absorbing and reflecting radiation without the need for matting. Several trackers can be used to increase the range and simplify the measurement sequence.

Coordinate measuring machines and optical scanners operating in an autonomous system are equipped with measurement space control systems for detecting undesirable objects in them, which also include people.

\section{Analysis in micro and nano scale}

Digitization in the area of micro and nano is based on completely different premises. Its purpose is not to identify geometry, but to highlight the most important features of surface unevenness, consisting in the calculation of a reference element and parameter values or functional characteristics. In this area the scale distinction is the most applicable. It boils down to the separation of individual components from the signal obtained from the surface.

There are a number of measurement techniques taking into account different physical properties, among which the contact and contact profilometry (e.g. using confocal heads), interferometric techniques (including scanning coherence interferometry), optical micro-copying (e.g. differentiation) are distinguished. focal, concentric) as well as microscopy based on atomic properties (scanning tunnel microscopy, atomic force microscopy, etc.). Some of these techniques allow for analysis at the nano and micro scale, others go beyond the micro and enter the meso scale.

Examples of instruments working on the micro and nano scale are shown in fig. 8.
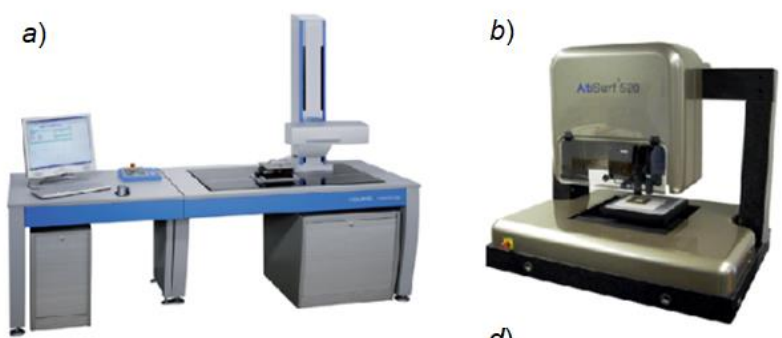

c)
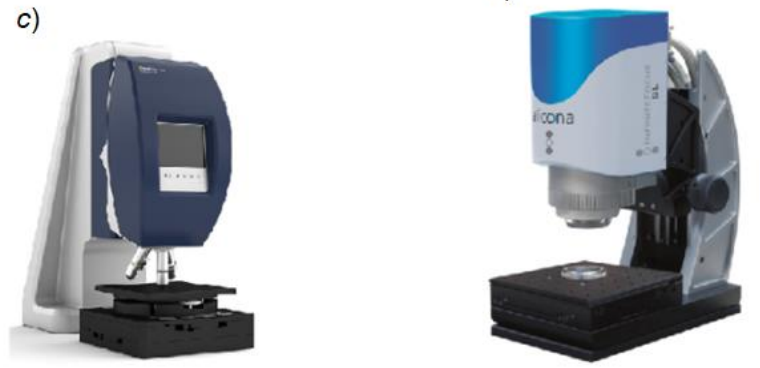

Fig. 8. Examples of measuring instruments operating in the micro scale: a) contact prophilometer, b) multi-sensor confocal profilometer, c) scanning coherence interferometer and $d$ ) focal distance microscope

Working on a signal related to inequalities, you can focus on a large or small scale, depending on the frequency band used. In the surface topography [10] standards, there is an $S$ filter that removes small scale horizontal components from the primary surface, and an $L$ filter that removes large-scale components. All parameters refer to a surface of limited scale, which can be treated as the surface S-F (after removing the shape) or S-L (after removing the shape and waviness). This is the first level to extract the scale from the signal.

Modern production often requires much more. Unevenness occurs on the surface under investigation, the cause of which is related to various phenomena and processes. Surface metrology allows it to be determined precisely by using the appropriate scale. The most common techniques are filtration, discrete wavelet transform (DWT) and discrete modal decomposition (DMD) [11].

Filtration is the simplest method. Apply, among others Gauss, Gauss resistant, wavelet, modal and morphological filters. You can also use different cut-off values (i.e. wavelengths from which the filter begins its operation).

Due to very different transfer bands, a number of its components can be separated from the surface, as shown in fig. 9 [12]. A resistant Gauss filter was used (respectively: HP - high-pass, LP - low-pass, BP - bandpass) with the cut-off value (in fig. 9 marked as L): 6, 9, 10, 13, 15, 19, 23, $29,36,45,56,74,99,127,178,297$ and $446 \mu \mathrm{m}$.

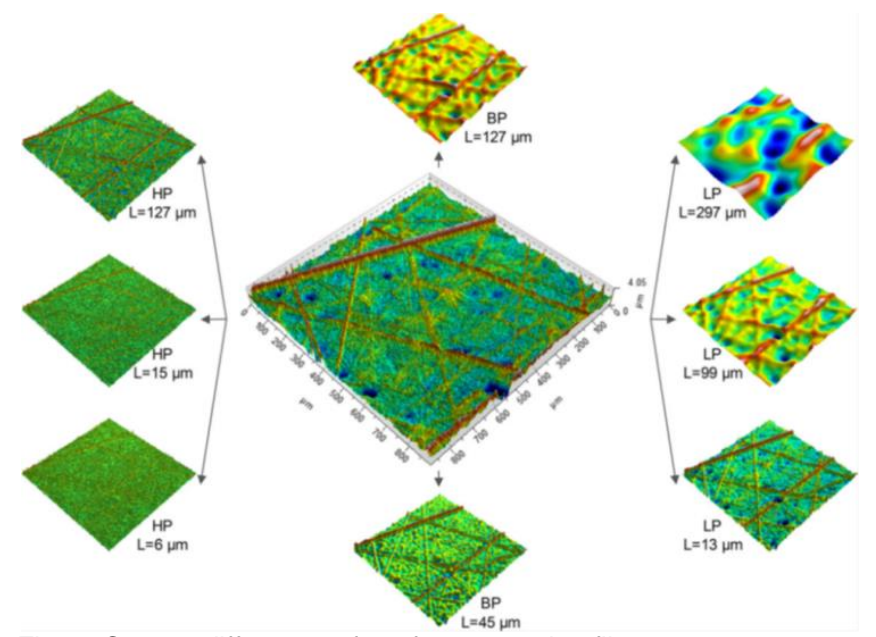

Fig. 9. Convex different surface features using filters

In this case, surface analysis was used to compare the materials used for replicas and the reliability of their replication. This technique is also very well suited for combining the functionality of measuring instruments used to analyze surface unevenness. The signal obtained from the same surfaces, divided into individual ranges of the micro scale, gives much better indications for the assessment than the values of the surface parameters shown by various instruments. It is possible to compare specific instruments for the given frequency of the signal obtained from the surface, and in other ranges such a combination is not possible.
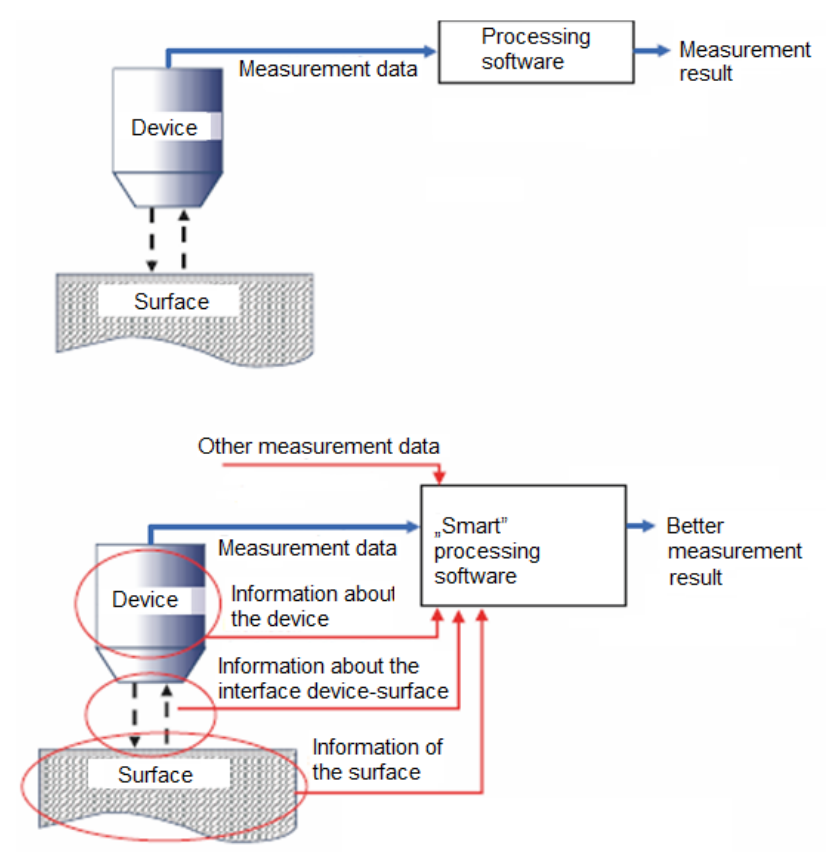

Fig. 10. Additional sources of information and changes in the flow of information when switching from a conventional approach to metrology of an information-rich surface 


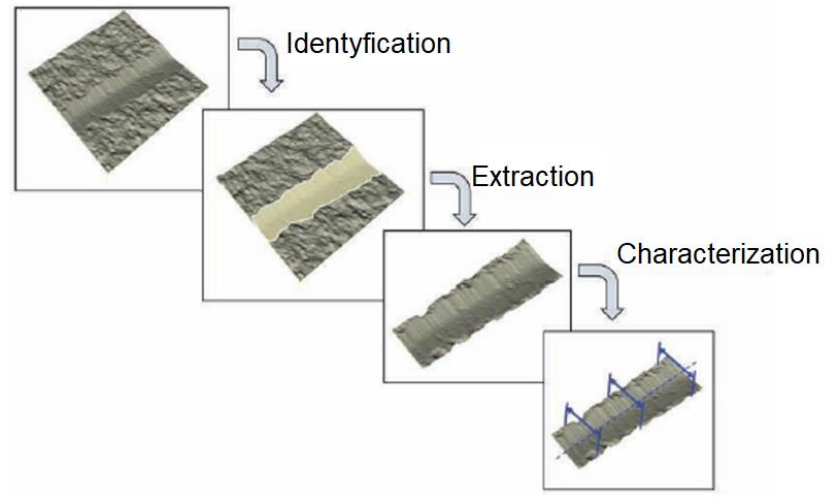

Fig. 11. Surface characterization based on features

This approach to the measurement of surface unevenness also fits into the recently developed metro-logic strategy of information-rich surface metrology, using not only the results of the measurement, but also knowledge related to its determinants. This is shown in fig. 10 [13].

Based on the metrology of the information-rich surface it is also possible to characterize the surface based on the features. It can be divided into three stages (example in fig. 11) [13]: identification of the feature (the feature is identified using the template of shape and size given in the reference information), isolation of the feature (isolation of features from the base set as an independent geometrical construct) and characterization features (description of the characteristic in terms of size, shape and parameters).

This approach to surface metrology seems an interesting tendency with good prospects for the future.

\section{Analysis in meso scale}

Digitization on the meso scale is a combination of both described previously. The meso scale is the result of the mentioned development of measuring instruments and the increase of measuring ranges. In addition to the devices for measuring deviations of shape, which traditionally were located halfway between the metrology associated with geometry features and the analysis of surface unevenness, new instruments appeared in recent years. On the one hand, these are constructions based on coordinate measuring machines, and on the other - on white light interferometers. Both of these solutions make it possible to measure both surface unevenness elements and certain geometrical features. Examples of devices working on the meso scale are shown in fig. 12.

In recent years, the most common application on the meso scale is simultaneous measurement of surface irregularities, shape deviations and selected geometrical features. For these purposes, the most common are: white light interferometer with a large range and focal length microscope. An exemplary image from a white light interferometer is shown in fig. 13.
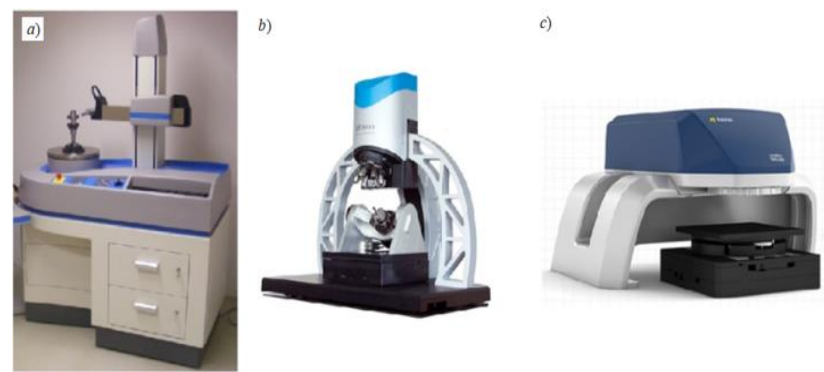

Fig. 12. Examples of measuring instruments operating in the meso scale: a) a device for measuring deviations, b) a microscope for focal differentiation, $c$ ) a scanning scanner with a large range of coherence

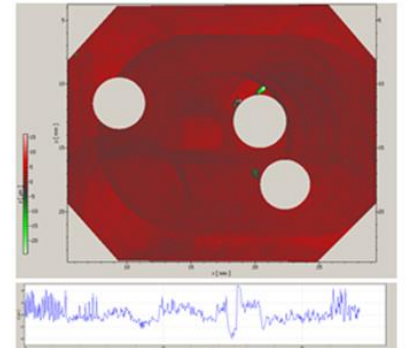

Surface

flatness and roughness

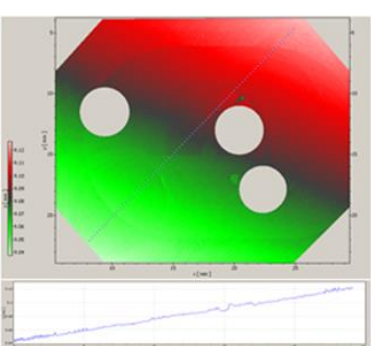

Parallelism

to the reference surface
Fig. 13. Image of deviations and irregularities on the milled surface obtained with the use of a large white light interferometer [14]

An interesting proposition of a device operating in the meso scale is also a focal point microscope constructed in the coordinate concept of a measuring machine. It has been prepared for multi-sensory measurements and enables the transition from three axes to five. The appearance of the machine and its measuring capabilities are shown in fig. 14.
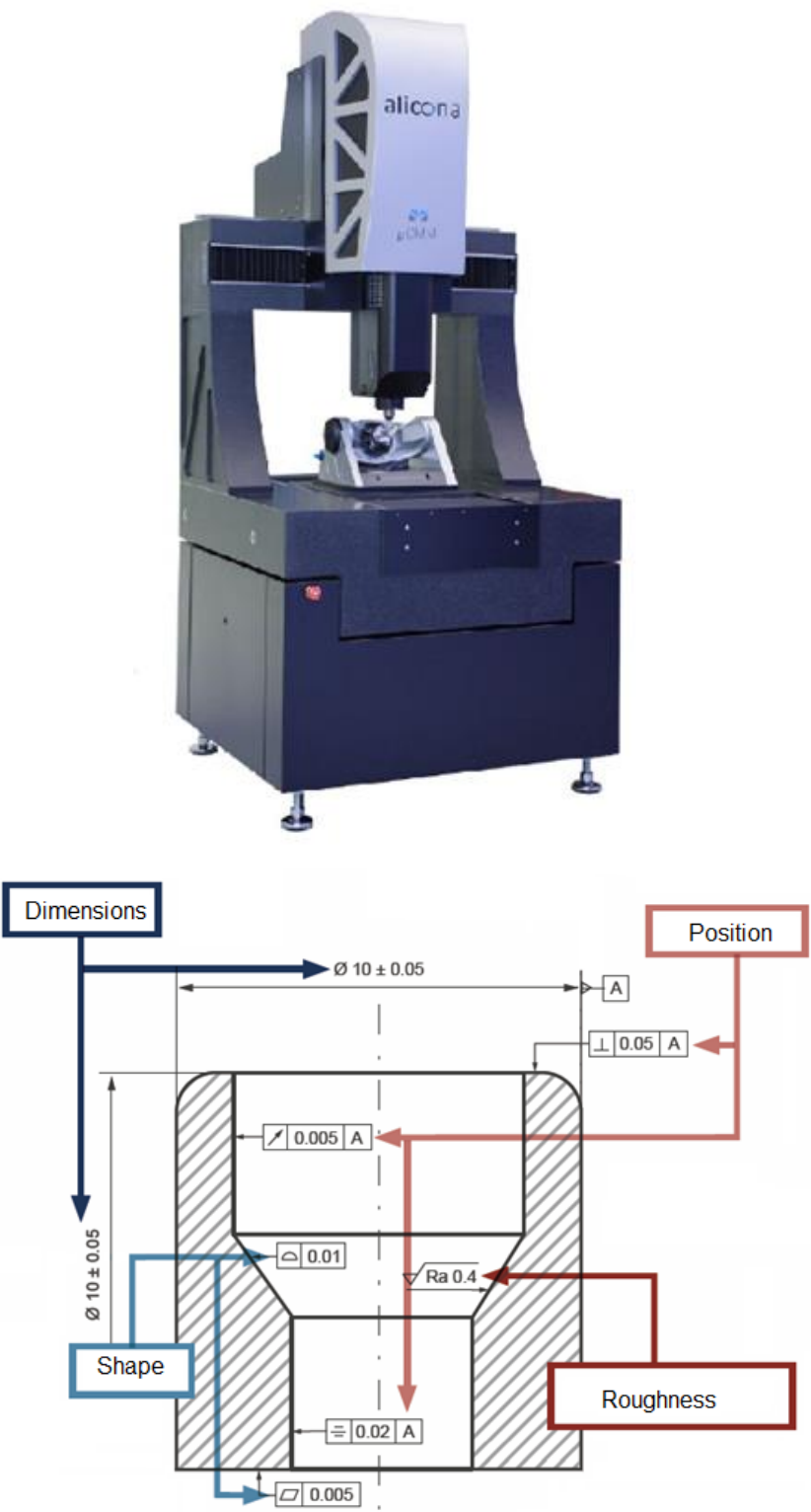

Fig. 14. Focal point differential microscope in the coordinate convention of a measuring machine and its measuring capabilities

The device has a maximum permissible length error of $0.8+\mathrm{L} / 600$, which is a very good result for such a construction of a moving portal machine. 


\section{Conclusions}

According to the Industry 4.0 strategy, metrology is to become a fully integral part of production, even if not all measurement systems will be physically embedded in the process. The main role will be played by automation, which will make the control of the finished product less and less frequent.

Active control, implemented during the production process with the help of a new generation of intelligent sensors, often integrated with production lines and manufacturing devices that allow current interference of artificial intelligence into the process, is a challenge not only for metrology, but also for sensory and more generally mechatronics. The steps for this purpose are the automatic calibration of measuring devices and work to simplify the software interfaces and data transfer capabilities between applications. This is crucial when creating smart factories in accordance with the approach taken from Industry 4.0.

Metrology of length and angle in different scales allows for the digitalization of the elements made, thanks to which it forms part of the big data philosophy. More and more often there are situations in which the manufactured element is analyzed on the basis of a deviation map, and its quality is perceived holistically at various scales. This trend will undoubtedly develop in the coming years.

Publication of this article was financed by the Ministry of Science and Higher Education as part of the project 02/22/DSPB/1432.

\section{REFERENCES}

1. http://www.dlahandlu.pl/technologie-i-wyposazenie/deloitte-polskanie-jestjeszcze-gotowa-na-czwarta-rewolucje-przemyslowa-68401.html.

2. Panek M. „Analiza dokładności odtwarzania kształtów swobodnych w inżynierii odwrotnej". Poznań: Wydział Budowy Maszyn i Zarządzania, Politechnika Poznańska, 2017.

3. https://www.polytec.com/int/surface-metrology/products/large-areameasuring-systems/tms-100-topmap-metrolab/ (access: 10.07.2018).

4. Wieczorowski M., Pawlus P., Mathia T. "Scale issue in length metrology". Proceedings of XIII International Scientific Conference Coordinate Measuring Technique. Bielsko-Biała, 2018.

5. Brown C.A., Charles P.D. "Fractal analysis of topographic data by the patchwork method". Wear. 161 (1993): pp. 61-67.

6. ASME B46.1-2003, Surface Texture, Surface Roughness, Waviness and Lay.

7. Ratajczyk E. "Tomografia komputerowa CT w zastosowaniach przemysłowych. Cz. "II. Tomografy i ich parametry, przykłady zastosowań". Mechanik. 3 (2011): pp. 226-231.

8. Gapiński B., Wieczorowski M., Marciniak-Podsadna L., Dybała B. Ziółkowski G. "Comparison of different method of measurement geometry using CMM, optical scanner and computed tomography 3D". Procedia Engineering. 69 (2014): pp. 255-262.

9. https://www.creaform3d.com/en/metrology-solutions/cube-r-automatedquality-control (access: 13.07.2018).

10. PN-EN ISO 25178-2 - Specyfikacje geometrii wyrobów (GPS) - Struktura geometryczna powierzchni: Przestrzenna - Część 2: Terminy, definicje i parametry struktury geometrycznej powierzchni, 2014.

11. LeGoïc G., Bigerelle M., Samper S., Favrelière H., Pillet M. "Multiscale roughness analysis of engineering surfaces: A comparison of methods for the investigation of functional correlations". Mechanical Systems and Signal Processing. 66-67 (2016): pp. 437-457.

12. Marteau J., Wieczorowski M., Xia Y., Bigerelle M. "Multiscale assessment of the accuracy of surface replication". Surface Topography: Metrology and Properties. 2, 2 (2014) 044002.

13. Senin N., Leach R. "Information-rich surface metrology". Commercial Micro Manufacturing International. 11, 4 (2018): pp. 26-39.

14. Wieczorowski M. „Pomiary nierówności powierzchni: metody i aplikacje”. Materiały Surface Forum, Spała (2018).

Translation of scientific articles, their computer composition and publishing them on the website www.mechanik.media.pl by original articles in Polish is a task financed from the funds of the Ministry of Science and Higher Education designated for dissemination of science. 